\title{
Glycogen storage disease due to liver phosphorylase kinase deficiency
}

INSERM

\section{Source}

INSERM. (1999). Orphanet: an online rare disease and orphan drug data base. Glycogen storage disease due to liver phosphorylase kinase deficiency. ORPHA:264580

Glycogen storage disease (GSD) due to liver phosphorylase kinase (PhK) deficiency is a benign inborn error of glycogen metabolism characterized by hepatomegaly, growth retardation, and mild delay in motor development during childhood. 